\title{
ESTUDO DA CURRICULARIZAÇÃO DA EXTENSÃO NO CENTRO UNIVERSITÁRIO NORTE DO ESPÍRITO SANTO
}

\section{STUDYING THE CURRICULAR INSERTION OF EXTENTION IN THE NORTHERN UNIVERSITY CENTER OF ESPÍRITO SANTO}

\author{
Carla Viviane Novais Cabral de Oliveira \\ ORCID: https://orcid.org/0000-0002-1721-2662 \\ Marielce de Cássia Ribeiro Tosta \\ ORCID: https://orcid.org/0000-0001-6037-4088
}

\section{Resumo}

O Plano Nacional de Educação (PNE) 2014-2024 instituiu, na estratégia 12.7, que deve ser creditado no currículo dos cursos de graduação no mínimo $10 \%$ do total de créditos curriculares em extensão. O objetivo deste artigo foi diagnosticar se os Projetos Pedagógicos dos Cursos de Graduação (PPCs) do Centro Universitário Norte do Espírito Santo (CEUNES) estão atendendo essa estratégia. Realizou-se um estudo exploratório, natureza qualitativa, caracterizado como estudo de caso. Para coleta de dados, ocorreu levantamento das ações extensionistas, análise dos PPCs e aplicação de questionários. Os resultados apontaram número baixo de ações registradas no Sistema de Informação; Extensão inserida como Atividades Complementares nos Projetos Pedagógicos e os Coordenadores de Curso e Presidentes dos Núcleos Docentes Estruturantes (NDE) necessitam discutir a forma de vincular as atividades extensionistas aos respectivos componentes curriculares. Este artigo é resultado de uma dissertação de Mestrado vinculada ao Programa de Pós-Graduação em Gestão Pública da Universidade Federal do Espírito Santo.

Palavras-chave: Extensão Universitária; Inserção curricular da extensão; Políticas Públicas.

\begin{abstract}
The National Education Plan (PNE) 2014-2024 established, in the strategy 12.7, that it is necessary to credit at least $10 \%$ of the total curricular credits of undergraduate courses in extention activities. This article aims to verify if the Pedagogical Projects of Undergraduate Courses (PPCs) of the Northern University Center of Espírito Santo (CEUNES) are accomplishing this strategy. It was carried out an exploratory study using qualitative research methods, characterized as a case study. Data collection was obtained through a survey of the extension actions, analysis of PPCs and questionnaires. The results show a small number of actions registered in the information system; the extension is inserted as complementary activities in the Pedagogical Projects; and the course coordinators and the presidents of the Structuring Teaching Nucleus (NDE) need to discuss how to link the extension activities to its respective curricular content. This study is the result of a Master's degreee dissertation linked to the Postgraduate Program in Public Management at the Federal University of Espírito Santo.
\end{abstract}

Keywords: University extension; Curricular insertion of extension; Public policies. 


\section{Introdução}

O Plano Nacional de Educação (PNE) constitui um documento que define compromissos colaborativos entre os entes federativos e diversas instituições pelo avanço da educação brasileira. As questões públicas que o motivam podem ser vislumbradas nas desigualdades educacionais, na necessidade de ampliar o acesso à educação e à escolaridade média da população, na baixa qualidade do aprendizado e nos desafios relacionados à valorização dos profissionais da educação, à gestão democrática e ao financiamento da educação (BRASIL, 2014).

Este plano está estruturado em quatro grupos principais de metas que podem ser definidas como as demarcações concretas do que se espera alcançar em cada dimensão da educação brasileira. Dentre estas, destaca-se a de número 12.7 , que preconiza o mínimo de $10 \%$ dos créditos curriculares revertidos em ações extensionistas voltadas para área social.

De forma a corroborar, o PNE, quanto à estratégia citada, o Conselho Nacional de Educação (CNE), vinculado ao Ministério da Educação, aprovou a Resolução $\mathrm{n}^{\circ}$. 7/2018 em que reafirma a necessidade de integralização curricular. A resolução trouxe, ainda, de forma expressa em seus capítulos sobre extensão: concepção, diretrizes, princípios, avaliação e registro. A normativa destacou que cada instituição de ensino superior deve organizar sua forma de cumprir o determinado na estratégia 12.7, estipulando prazo de três anos a contar da homologação (18/12/2018).

Apesar da previsão legal de creditação curricular de programas e projetos de Extensão nos currículos do ensino superior, a prática não está ocorrendo da forma determinada. Por isso, o Fórum de Pró-Reitores de Extensão das Instituições Públicas de Educação Superior Brasileiras (FORPROEX) ${ }^{i}$ promoveu um mapeamento do processo de curricularização nas universidades brasileiras em maio de 2019. Das 141 IES, apenas 68 participaram da pesquisa e constatou-se que elas se encontram em fases variadas do processo de curricularização, conforme segue: 42 iniciando discussões; 6 não iniciaram, 18 em fase de implantação; e 2 finalizaram o processo e estão em execução da meta 12.7 (RENEX, 2019).

Cabe ressaltar que o cumprimento dos referidos preceitos legais vem ao encontro do princípio da indissociabilidade, ensino, pesquisa e extensão, o qual já havia sido previsto na Constituição Federal de 1988, em seu artigo 207. No entanto, o conceito e as classificações das ações extensionistas não são claros, o que se percebe desde sua concepção nas instituições, em 1914, até as atuais discussões realizadas no FORPROEX e na necessidade de criação de leis para o alcance de sua institucionalização.

Considerando este conceito e as normas vigentes do PNE 2014/2024 e da Resolução n . 7/2018, vê-se um destaque para curricularização da extensão. De acordo com Imperatore et al. (2015), a prática desse termo é a ressignificação do ensino superior e o reconhecimento da extensão como função acadêmica integrada ao currículo, pois o que se observa, até então, é a inclusão, desta, como atividades complementares. Benetti et al. (2015) afirmam que a comunidade acadêmica tem a oportunidade de rever os conceitos praticados referentes às ações de extensão, de forma que propicie maior interação com a sociedade e coloque o aluno como sujeito ativo, capaz de transmitir e, ao mesmo tempo, receber conhecimento. 
Silva e Cândido (2014) argumentam que a extensão assume papel fundamental dentro das instituições, pelo fato de a mesma ser o terceiro suporte no tripé, uma vez que foi a última a entrar nesse processo, que mais estreita o elo que deve existir das práticas acadêmicas com a comunidade que as circundam. Ela oportuniza a academia a fazer uma devolutiva à sociedade, seja por meio de melhores profissionais ou intervenções diretas em contribuições das demandas sociais.

Ao observar a importância da extensão no meio acadêmico, bem como a necessidade do cumprimento da política educacional, notou-se a viabilidade de pesquisar e contextualizar se os Projetos Pedagógicos dos Cursos (PPC) de Graduação do Centro Universitário Norte do Espírito Santo (CEUNES) da Universidade Federal do Espírito Santo (UFES) estão em consonância ao cumprimento legal da creditação curricular da extensão.

Diante dessa problemática, o objetivo deste artigo foi analisar quanto à inserção de atividades de extensão nos currículos pedagógicos dos cursos de graduação da UFES Campus São Mateus, conforme estabelece a estratégia 12.7 do PNE (2014-2024).

Visando alcançar respostas quanto ao problema anteriormente apontado, foram objetivos específicos, ainda: quantificar o número e a evolução, desde 2006, do registro de ações de extensão do CEUNES no Sistema de Informação da Extensão (SIEX); identificar quais os PPCs possuem Extensão Universitária, conforme estabelecido no PNE-2014 e Resolução no . 7/2018 e verificar, junto ao Presidente do Núcleo Docente Estruturante (NDE) dos colegiados e Coordenadores de Cursos de Graduação o conhecimento e ou ações quanto à meta (12, estratégia 12.7) estabelecida no PNE (2014-2024).

\section{A Curricularização da Extensão e seus preceitos legais}

Os estudos, no Brasil, sobre creditação da Extensão (termo usado no início das discussões) tiveram sua origem, segundo Santos (2017), em 1991, no V FORPROEX. A partir desta época, surgiu a possibilidade de operacionalizar as atividades extensionistas dentrodos Currículos (PNEX, 2000/2001, p. 9). A Curricularização da Extensão tem um arcabouço legal, produzido pelo FORPROEX e Conselho Nacional de Educação (CNE), o qual vem se apresentando de forma histórica para as universidades.

A temática vem se sustentado nas seguintes bases: Constituição Federal de 1988, Art. 207, quando prevê para as universidades autonomia didático-cientifica, administrativa e financeira e a indissociabilidade do ensino-pesquisa-extensão; LDB/1996, que traz a extensão como elemento obrigatório na formação do aluno e nos registros dos PPCs; Política Nacional de Extensão de 2012, este assume importante papel quando atualiza o conceito e propõe diretrizes para ações de Extensão; Plano Nacional de Educação (PNE) para os decênios 20012010 e 2014-2024; e Resolução n ${ }^{\circ}$. 7/2018, que estabelece as diretrizes para a Extensão e regimenta o disposto na estratégia 12.7 da Lei n ${ }^{\circ}$. 13.005/2014 (PNE-2014-2024).

É a partir do PNE (2001-2010 e 2014-2024) que as IES iniciam as discussões acerca da inclusão formal das atividades extensionistas nos PPCs. O PNE (2001-2010), constituído 
pela Lei 10.172 , de 09 de janeiro de 2001, teve seu eixo estruturado na implantação de políticas e programas que pretendiam melhorar a educação. Ele se concentrou em demoratizar o ensino superior, fazendo com que se aproximasse do mercado de trabalho. A partir dele, foi dado início à formalização da extensão nos Currículos. A meta 23, deste PNE, expressou a creditação de, no mínimo, $10 \%$ em ações extensionistas, em que o aluno deveria atuar de forma efetiva e não ser somente participante (ZANFERARI; ALMEIDA, 2017).

Esta meta trouxe a creditação de forma abrangente, quando citou sobre ações extensionistas, ou seja, trata-se daquelas ações discriminadas pelo FORPROEX (2007), que são: eventos, cursos, prestações de serviços, projetos e programas. Igualmente, limitou que a previsão de aplicação do percentual mínimo de créditos das ações nos currículos ocorreria apenas para as universidades.

A Lei 13.005/2014, de 25 de junho de 2014, que institui o PNE 2014-2024, trouxe novamente a questão, mas com outra redação e mesma intencionalidade, na sua meta 12 , estratégia 12.7 , a integração de, no mínimo, $10 \%$ do total de créditos curriculares exigidos para graduação em programas e projetos de extensão universitária, preconizando ações de forma exclusiva, para áreas de grande relevância social (BRASIL, 2014). Ressalta-se que, na nova redação, utilizou para a creditação apenas as ações classificadas como programas e projetos e a determinou para todas as IES.

Para Imperatore et al (2015), a estratégia 12.7 do PNE vigente vem romper paradigmas da construção curricular de forma compartimentada em disciplinas, do ensino limitado à sala de aula. Ela vem provocar uma construção de práticas sociais que poderão levar ao exercício individual ou coletivo de cidadania, a redefinição de currículo a partir da Extensão e, até mesmo, da universidade brasileira. A fim de alcançar a previsão legal da meta 12.7, para que ela não seja tratada apenas como previsão, como mera intenção política, foi estabelecido no PNEX (2011-2020) estratégias:

\footnotetext{
Meta 1: Incorporar até 2015 ao menos 10\% do total de horas curriculares de formação acadêmica em programas e projetos de extensão fora dos espaços de sala de aula.

1.1) Estimular o reconhecimento da extensão em sua dimensão pedagógica e como elemento de construção do conhecimento no âmbito dos fóruns competentes;

1.2) Fomentar a criação de componentes curriculares em ações de extensão integradas aos currículos das formações em níveis de graduação;

1.3) Reconhecer horas de integralização curricular pela atuação em projetos e programas de extensão;

1.4) Promover o exercício da indissociabilidade entre ensino, pesquisa e extensão de forma a assegurar a dimensão acadêmica da extensão na formação dos estudantes;

1.5) Criar mecanismos para reconhecimento dos espaços de extensão na condução de pesquisas (BRASIL, 2011, p.2).
}

A importância dada ao PNE (2014) levou o PNEX (2011-2020) a reforçar o alcance da curricularização da extensão, fazendo menção em outras metas, como a 7 e a 10, as quais estabelecem financiamento da extensão e inclusão nos projetos pedagógicos de cursos de graduação a extensão, respectivamente. 
Em 18 de dezembro de 2018, foi publicada a Resolução $n^{\circ} 7$ do CNE, que estabeleceu princípios, fundamentos e procedimentos para o planejamento da Extensão nas IES e regulamentou o dispositivo da meta 12.7 do referido PNE. Trata-se de um documento orientador para as reformulações nos PPCs, pois as universidades têm autonomia para criar suas próprias regras, a fim de atingir o objetivo da curricularização dentro do prazo estipulado: 18 de dezembro de 2021 .

Esta Resolução ainda estabelece uma base regimental para a Meta 12.7 do PNE (20142024), ou seja, operacionaliza a forma de execução das atividades de extensão nos currículos do Ensino Superior Brasileiro; estabelece o conceito, princípios e padrão de organização da Extensão para todo o ensino superior do país, deixando claro em seu Art. $4^{\circ}$ que as atividades extensionistas, obrigatoriamente, devem ser inseridas na matriz curricular dos cursos e no Art. $7^{\circ}$ que as referidas atividades obrigatoriamente devem envolver, de forma direta, as comunidades externas e devem ser vinculadas à formação do estudante (RENEX, 2019).

Outro destaque, a partir dessa normativa, é que o Instituto Anísio Teixeira (INEP), para fins de autorização, reconhecimento e renovação de curso, assim como credenciamento e recredenciamento das IES, passa a considerar a curricularização da extensão como elemento avaliativo.

A partir da Resolução n ${ }^{0}$. 7/2018, a Extensão evoluiu em seu conceito e passou a ser definida como:

\begin{abstract}
Atividade que se integra à matriz curricular e à organização da pesquisa, constituindose em processo interdisciplinar, político educacional, cultural, científico, tecnológico, que promove a interação transformadora entre as instituições de ensino superior e os outros setores da sociedade, por meio da produção e da aplicação do conhecimento, em articulação permanente com o ensino e a pesquisa (BRASIL, 2018, p.1).
\end{abstract}

A evolução do pensar, na prática extensionista, trouxe para 2019 reflexões não somente conceituais, mas também quanto ao protagonismo da ação de extensão, público-alvo e dilemas relacionados ao fomento da extensão. Hoje, deve ser incorporado pela comunidade acadêmica que a extensão possui três protagonistas: a instituição, o discente e o docente. Para Deboni (2019), o papel do aluno não deve ser, somente, de mero expectador da prática extensionista estabelecida pelo professor. Ele é um sujeito ativo da ação e deve ser visto dessa forma.

Quanto ao público a ser beneficiado com as ações, deve-se pensar que não se faz Extensão de portas fechadas, mão única, tendo apenas um beneficiário: o aluno. O grau de envolvimento da universidade com a sociedade não poderá se perder na prática extensionista, muito pelo contrário, o envolvimento deve ser fortalecido pela Extensão a fim de proporcionar resultados positivos para ambos.

Sendo o PNE uma política educacional herdeira de uma longa discussão do FORPROEX, no que diz respeito à Extensão, com a efetivação do Plano referente ao decênio de 2014, meta 12.7, surgiu a necessidade de promover discussões e, consequentemente, revisões nos PPCs dos cursos de graduação, pois os mesmos precisam contemplar o percentual mínimo de $10 \%$ do total da carga horária do respectivo curso, créditos curriculares em programas e projetos de extensão. 
Para fins de curricularização, cada curso deverá indicar, em seu Projeto Pedagógico, a forma como os discentes deverão praticar as atividades de extensão. Elas deverão exercer um papel formativo na vida do estudante e colocá-lo como "ator" principal no desenvolvimento das ações, bem como envolver a comunidade externa.

Para tanto, as estruturas curriculares precisarão ser analisadas para que a creditação da extensão não seja apenas vista como cumprimento legal, como uma adição de disciplina no currículo (disciplina de Extensão) ou redução de carga horária das disciplinas. As ações para curricularizar deverão perpassar pela criatividade de reformulação das disciplinas passíveis de acolher a extensão e promover mudanças no currículo.

\section{Práticas da Curricularização da Extensão nas IES}

De acordo com a RENEX (2019), o número de IES cadastradas no FORPROEX, até agosto de 2019, era de 143, sendo 63 Universidades Federais. Das IES federais, ressalta-se que é reduzido o número das que possuem experiências na curricularização da extensão, como também Resoluções, para normatizar os seus procedimentos, como pode ser visualizado na Figura 1.

Figura 1 - Universidades que possuem Resoluções sobre Curricularização até o mês de setembro de 2019

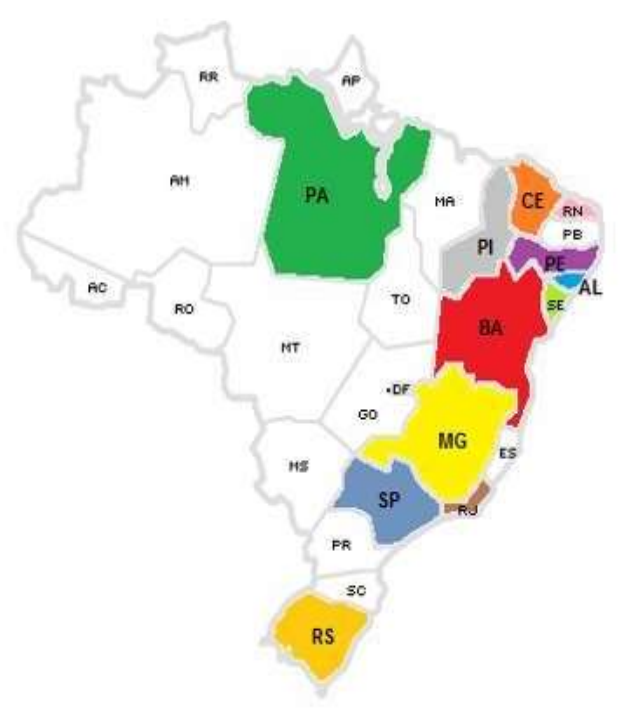

\begin{tabular}{|c|l|c|}
\hline \multirow{2}{*}{ U.F. } & \multicolumn{1}{|c|}{ UNIVERSIDADES } & RESOLUÇÃO \\
\hline AL & Universidade Federal de Alagoas & $04 / 2018$ \\
\hline \multirow{2}{*}{ BA } & Universidade Federal da Bahia & $01 / 2013$ \\
\cline { 2 - 3 } & Universidade Federal do Sul da Bahia & $06 / 2018$ \\
\hline & Universidade Federal do Recôncavo da Bahia & $06 / 2019$ \\
\hline \multirow{2}{*}{ CEE } & Universidade Federal do Ceará & $28 / 2017$ \\
\hline & Universidade da Integração Internacional da Lusofonia Afro-Brasileira & $08 / 2019$ \\
\hline \multirow{2}{*}{ MG } & Universidade Federal do Cariri & $42 / 2019$ \\
\cline { 2 - 3 } & Universidade Federal de Minas Gerais & $12 / 2015$ \\
\hline PA & Universidade Federal de Juiz de Fora & $04 / 2018$ \\
\hline PE & Universidade Federal de Pernambuco & $301 / 2019$ \\
\hline PI & Universidade Federal do Piauí & $09 / 2017$ \\
\hline RJ & Universidade Federal do Rio de Janeiro & $53 / 2019$ \\
\hline \multirow{2}{*}{ RN } & Universidade Federal do Rio Grande do Norte & $02 / 2013$ \\
\hline \multirow{2}{*}{ RS } & Universidade Federal de Pelotas & $25 / 2017$ \\
\cline { 2 - 3 } & Universidade Federal de Santa Maria & $38 / 2019$ \\
\hline SE & Universidade Federal de Sergipe & $06 / 2016$ \\
\hline SP & Universidade Federal de SP & $03 / 2019$ \\
\hline & & $12 / 2018$ \\
\hline
\end{tabular}

Fonte: Elaborado pela autora a partir do RENEX/2019.

A Universidade Federal do Rio de Janeiro (UFRJ) foi a primeira universidade a creditar à extensão nos currículos dos cursos de graduação. Ela promovia discussões internas para realizar esta prática, desde o PNE referente ao decênio 2001-2010, pois já trazia o percentual de 10\% em extensão na grade curricular. Após a publicação do PNE 2014-2024, 
a UFRJ publicou a Resolução $n^{\circ}$. 02/2013 e criou um Guia para facilitar os trabalhos dos coordenadores de cursos quanto à forma de realizar a inserção da extensão nos currículos e, consequentemente, cumprir o estabelecido na meta 12.7 desse PNE (PR-5/UFRJ).

A estratégia adotada pela UFRJ foi a realização de reuniões com os Coordenadores de Curso de Graduação e de Extensão, a fim de sensibilizá-los. Houve aplicação de questionário eletrônico e identificação dos tipos de disciplinas (obrigatórias, eletivas) ou Requisitos Curriculares Suplementares (RCS), por meio da Pró-Reitoria de Graduação (PROGRAD). Somente após esse levantamento, foi elaborada proposta de Minuta de Resolução para regulamentar a curricularização da extensão, Resolução nº. 02/2013 (BENETTI et al., 2015).

Outra Universidade que teve destaque na articulação de implementar a meta 12.7 foi a Universidade Federal da Bahia - UFBA. Em 1997, essa instituição criou o Programa UFBA em Campo, depois convertido em Atividade Curricular em Comunidade (ACC). Em 2013, o programa se transformou em Ação Curricular em Comunidade e em Sociedade (ACCS), sendo este utilizado para promover a integralização curricular da extensão nos cursos de graduação e pós-graduação. A ACCS é uma disciplina e tem a "responsabilidade" de promover o contato entre a academia e a sociedade; possuí carga horária mínima de 17 horas, relacionando-se com todas as disciplinas.

Carneiro et al. (2014) relata a experiência da Universidade Federal de Minas Gerais (UFMG). Em 2011, ela iniciou os trabalhos de creditação tendo como base as suas normativas internas. Foi realizado um diagnóstico junto aos colegiados de cursos, análise dos PPCs e da estrutura curricular pela Pró-Reitoria de Graduação e a Pró-Reitoria de Extensão/UFMG. Os resultados obtidos foram que, dos 80 cursos, 65 tinham previsão; 12 sem previsão e 3 não obtinham informação, mostrando a potencialidade dessa instituição em lidar com a indissociabilidade do ensino-pesquisa-extensão. Apesar disso, os autores destacaram que os créditos gerados pelos cursos que possuem previsão nos currículos, são insuficientes para cumprir a previsão legal do PNE-2014-2024.

A Universidade Federal de Pelotas -UFPel iniciou seus trabalhos após a publicação do PNE- 2014-2024, com a criação de uma comissão interna, a qual ficou responsável pelos estudos das normativas e de todo processo de discussão com os coordenadores de curso. Esta comissão buscou apoio nas duas instituições que já eram ativas na prática de curricularizar: UFRJ e UFBA. Vale ressaltar que esse auxílio não ficou limitado somente à participação presencial dos representantes daquelas universidades nos Seminários e mesa redonda, eles também colaboraram na redação da Resolução (PREC/UFPel, 2014).

A Universidade Federal de São Paulo (UNIFESP) realizou uma metodologia similar à UFPel, ou seja, optou em formar uma comissão para discutir e implementar a curricularização no período de 2015 a 2017, envolvendo equipes das Pró-Reitorias de Extensão e de Graduação. Foram realizados levantamentos quanto aos métodos utilizados em outras universidades, projetos e programas sociais de extensão realizados na UNIFESP. A Comissão escolheu 2 cursos por campus, os quais eram realizados nos 3 turnos e contemplavam áreas diferentes do conhecimento. Estes tiveram seus PPCs analisados para fins de identificação ou inserção da extensão. A análise 
foi realizada juntamente com coordenadores dos cursos, representantes do NDE, coordenadores das Câmaras de Graduação e Câmaras de Extensão de cada campus (PROEX/UNIFESP, 2015).

O processo de curricularização das atividades de extensão na Universidade Federal de Alagoas (UFAL) iniciou com a inclusão de uma meta no seu PDI (2013-2017): extensão como obrigatória no currículo. A metodologia utilizada foi incluir este tema no Programa de Formação Continuada em Docência do Ensino Superior da Pró-Reitoria de Gestão de Pessoas -PROGEP. A partir daí, foi possível sensibilizar e estabelecer diálogo com o corpo docente sobre a meta 12.7 do PNE (2014) e promover palestras e cursos sobre estratégias de curricularização. Nessa instituição ficou o encargo de cada curso definir como a extensão iria fazer parte do currículo (PROEX/UFAL, 2016).

\section{Procedimentos Metodológicos}

Quanto à abordagem, a pesquisa utilizou a qualitativa. De acordo com Godoy(1995), esta abordagem procura entender o fenômeno no seu ambiente natural, os fatos sociais são observados e incluídos no contexto ao qual pertencem. Esta abordagem foi utilizada de modo a atender o objetivo específico quanto à análise do conhecimento dos Coordenadores de Curso de Graduação e Presidentes dos NDEs quanto à meta estabelecida no PNE (2014-2024), em sua meta 12 , estratégia 12.7 .

No que diz respeito à natureza da pesquisa, classificou-se como aplicada. Gerhardt $\mathrm{e}$ Silveira (2009) dizem que é o tipo que produz conhecimento para aplicação prática direcionada para soluções de problemas específicos, no caso, a curricularização da extensão no CEUNES. Baseada na interpretação de Gil (2010), quanto aos objetivos, pautou-se no método de pesquisa exploratória, uma vez que o propósito era adquirir contato com o tema pesquisado.

Para os procedimentos, no primeiro momento, recorreu-se à pesquisa bibliográfica $\mathrm{e}$ documental, buscando os principais conceitos que circundam a extensão universitária e curricularização da extensão no Brasil, como também o seu arcabouço legal. O Estudo de caso foi a modalidade de pesquisa, pois focalizou na identificação e descrição das atividades de extensão do CEUNES, entre os anos de 2006/2 e 2019/1, como também as perspectivas e desafios quanto à curricularização da extensão.

A fim de conhecer sobre a aplicação do PNE (2014-2024) nas Universidades Federais do país, foram verificadas, a partir da lista das IES disponível no site da RENEX, quais destas possuíam resoluções sobre a temática. Os acessos foram realizados no período de 02 a 16 de setembro de 2019, direto na página de cada universidade e, ou diretamente na página das PróReitorias de Extensão. O critério de busca foi utilizando as palavras chave "Resolução de curricularização" ou "curricularizar a extensão" ou "creditação da extensão".

Quanto ao número de registro de ações de extensão realizadas no CEUNES, no período compreendido de 07/08/2006 até 30/06/2019, foi consultado o SIEX da Pró-Reitoria de Extensão. O sistema de gerenciamento de dados de extensão na UFES: o SIEX, foi substituído em 24/04/2019 em todos os Campi, contudo houve registros de ações até 
30/06/2019. No uso do sistema houve alguns problemas dentre eles: em 2010 e 2011, o SIEX sofreu atualização com possíveis perdas de dados; em 2013 houve migração de informações, ficando, comprometida, adesão pelos usuários (RELATÓRIO DE EXTENSÃO, 2017). O levantamento dos dados utilizados na pesquisa foi realizado com auxílio técnico da TI.

Para análise dos PPCs, foi solicitado acesso aos arquivos da PROGRAD /Departamento de Desenvolvimento Pedagógico (DDP). Tal atitude justifica-se pelo fato dos cursos de graduação do CEUNES possuírem estes documentos em fase de tramitação junto àquele departamento facilitando assim a pesquisa. A Instrução Normativa ${ }^{\circ}$ 004/2016 da PROGRAD/ UFES, estabelece diretrizes para elaboração dos PPCs da UFES, e determina uma estrutura formal para todos os documentos.

De modo a verificar se os PPCs do CEUNES atendem a Meta 12 e as resoluções citadas neste trabalho foi elaborado um check-list para analisar de forma específica os itens 4 (na matriz curricular - disciplinas obrigatórias, ementas) e 5 (extensão no Curso). Quanto ao entendimento dos coordenadores de curso de graduação e presidentes dos NDEs do CEUNES sobre extensão universitária, foi aplicado um questionário com 10 questões objetivas e 9 questões discursivas. Com este, pretendeu-se diagnosticar: conhecimento das ações de extensão nos respectivos cursos; relação das ações de extensão com a formação acadêmica dos alunos; conhecimento da obrigatoriedade legal da meta 12, estratégia 12.7 do PNE (20142024); de que forma podem inserir a extensão nos currículos dos cursos de graduação; quais são as principais dificuldades para essa implantação e como superá-las e de que forma poderá ser registrada a creditação nos currículos dos cursos de graduação do CEUNES.

Este instrumento de pesquisa foi aplicado aos 16 coordenadores de curso de graduação e aos 15 presidentes do NDEs do CEUNES, com mandatos vigentes e, ou pelo menos 6 meses de atuação na função. A escolha dos respondentes justificou-se pelo fato deles possuírem uma parcela de responsabilidade institucional, enquanto ocupantes das funções na construção coletiva dos respectivos PPCs.

O Projeto de pesquisa foi submetido ao Comitê de Ética do CEUNES através do site da Plataforma Brasil, obtendo o Certificado de Apresentação para Apreciação de ÉticaCAAE 16490619.6.0000.5063. A pesquisa está cumprindo todos os preceitos éticos para estudos científicos realizados com seres humanos.

\section{Análise dos dados e discussão dos resultados}

De acordo com o SIEX a Universidade, no período de 07/08/2006 até 30/06/2019, registrou 1.613 ações de extensão. Constata-se que as ações de extensão classificadas como Projetos foram as mais significativas (47\%) seguidas dos Eventos (28\%), Cursos (17\%) e Programa (8\%). A Prestação de Serviço teve apenas 3 registros.

Evidenciou-se, nos anos iniciais, um número reduzido de registros. Posto isso, conforme Relatório de Gestão (2008-2011), a PROEX dedicou-se em fortalecer a política institucional de Extensão, estender os serviços prestados pela Universidade e aumentar os 
laços com a sociedade por meio da Extensão. Urgia a necessidade de estabelecer estratégias que promovessem o "fazer extensionista" e seus registros, pois isso não estava ocorrendo de acordo com os números lançados no SIEX. Acertos técnicos no Sistema, foi outra ação estabelecida pela UFES, a fim de melhor acompanhar os números produzidos.

Em 2018, as ações apresentaram um crescimento de 12,5\% em relação ao ano anterior. Entretanto, não houve destaque, no Relatório de Gestão da PROEX, de intervenções que pudessem justificar esse aumento. Mas, o ano foi marcado por iniciativas dessa Pró-Reitoria no intuito de discutir a estratégia 12.7 (PNE 2014-2024) juntamente com a PROGRAD assim como iniciar o processo de discussão para substituir o SIEX.

Quanto às áreas temáticas, as ações da UFES estão inseridas em mais da metade (57,5\%) em Educação (29,5\%) e Saúde (28\%), índice que se reproduz no período estudado (agosto/06 a junho/19).

O CEUNES representa $10 \%$ dessas ações no período citado, conforme descrito a seguir (PROEX, 2019). Este Centro, por sua vez, foi criado em 2006, com 9 cursos de graduação, e somente a partir de 2008 foram criados Departamentos ${ }^{\text {ii }}$.

No SIEX foram registradas poucas ações de extensão nos primeiros anos de atividades no campus, conforme pode ser verificada a evolução de ações anuais apresentadas no Gráfico 1, elaborado a partir de dados fornecidos pelo SIEX (2019).

Gráfico 1 - Histórico das ações extensionistas do CEUNES cadastradas no SIEX

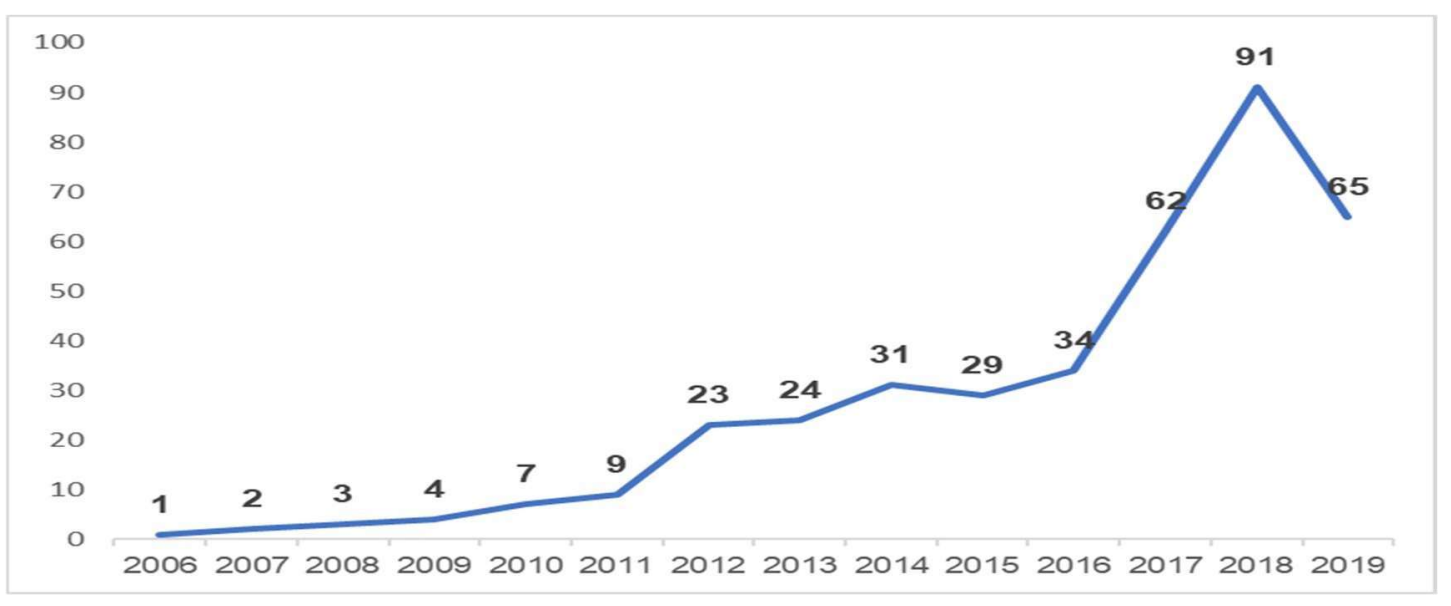

Fonte: Elaborado pela autora a partir do SIEX/2019.

A baixa produção nos anos iniciais é justificada, inicialmente, pelo fato de existir poucos Departamentos e servidores no CEUNES. Entretanto, no decorrer dos anos, a evolução dos registros no SIEX também não ocorreu, fato este que pode ser justificado pelos mesmos motivos que a PROEX apresenta nos Relatórios de Gestão de Extensão para os demais Centros de Ensino da UFES. 
Ressalta-se que, mesmo após as ações estabelecidas pela PROEX, a fim de levar os usuários a alimentar o SIEX e a publicação do PNE (2014-2024), não houve evolução nos registros das ações no CEUNES, a partir desses atos. Somente a partir do ano de 2017, observa-se que o campus apresenta um crescimento nos registros de Extensão.

Quanto à distribuição de ações por Departamentos do CEUNES, identificou-se que os de Educação (DECH, 39\%) e Saúde (DCS, 33\%) são os responsáveis pela maior produção, fato que corrobora com as principais áreas temáticas escolhidas, tanto no Centro, como também nos demais campi da Universidade. Foi possível verificar que as maiores produções individuais são dos docentes lotados no Departamento de Engenharias e Departamento de Matemática Aplicada. Esse resultado vai de encontro ao estabelecido por Carneiro et al. (2014) que diz que os docentes dos cursos das áreas tecnológicas são os que menos promovem extensão, seja pelo próprio perfil ou dos alunos que optam pelos cursos de exatas.

Outro apontamento, baseado na aplicação de filtros no Sistema, é que um pequeno número do corpo docente do campus $(32 \%)^{\text {iii }}$ se envolve com extensão. Tal fato pode demonstrar uma fragilidade no desenvolvimento da indissociabilidade do ensino-pesquisaextensão instituído pela Constituição Federal Brasileira/88 e que, apesar do empenho do FORPROEX em institucionalizar a Extensão, o processo não ocorre de forma tão rápida e clara para os profissionais que atuam na "ponta" deste Centro de Ensino Superior.

Das ações registradas, considerando os programas, projetos, cursos, eventos e prestação de serviço, em suas oito áreas temáticas de atuação, constata-se que as maiores incidências recaem sobre as de educação e saúde. A prática de ações destinadas aos direitos de primeira geração (PAULA, 2013) não é prerrogativa apenas do CEUNES, mas também de outros campi da Universidade.

Essa tendência do CEUNES, em desenvolver mais ações classificadas como direitos de primeira geração, está relacionada com a história da Extensão no Brasil e suas concepções, principalmente a assistencialista (MELO NETO, 2002; ALMEIDA, 2011; NOGUEIRA, 2013; DEUS; HENRIQUES, 2017). Ademais, as temáticas que apresentam maior percentual são aquelas que recaem nos maiores desafios para o desenvolvimento de políticas públicas.

Os registros do SIEX permitiram elaborar o Gráfico 2 a fim de se ter uma visão ampla das ações distribuídas por áreas. Observa-se que a maior concentração de extensão está nos Projetos com destaque para temática de Educação (38\%) e Saúde (33\%) e um dos menores índices está em Programas. Quanto à distribuição das demais áreas, os dados demostram que Trabalho, Comunicação, Direitos Humanos e Cultura possuem uma participação inferior a $3 \%$ da produção extensionista no CEUNES. 
Gráfico 2 - Distribuição de ações e áreas temáticas da produção extensionista do CEUNES

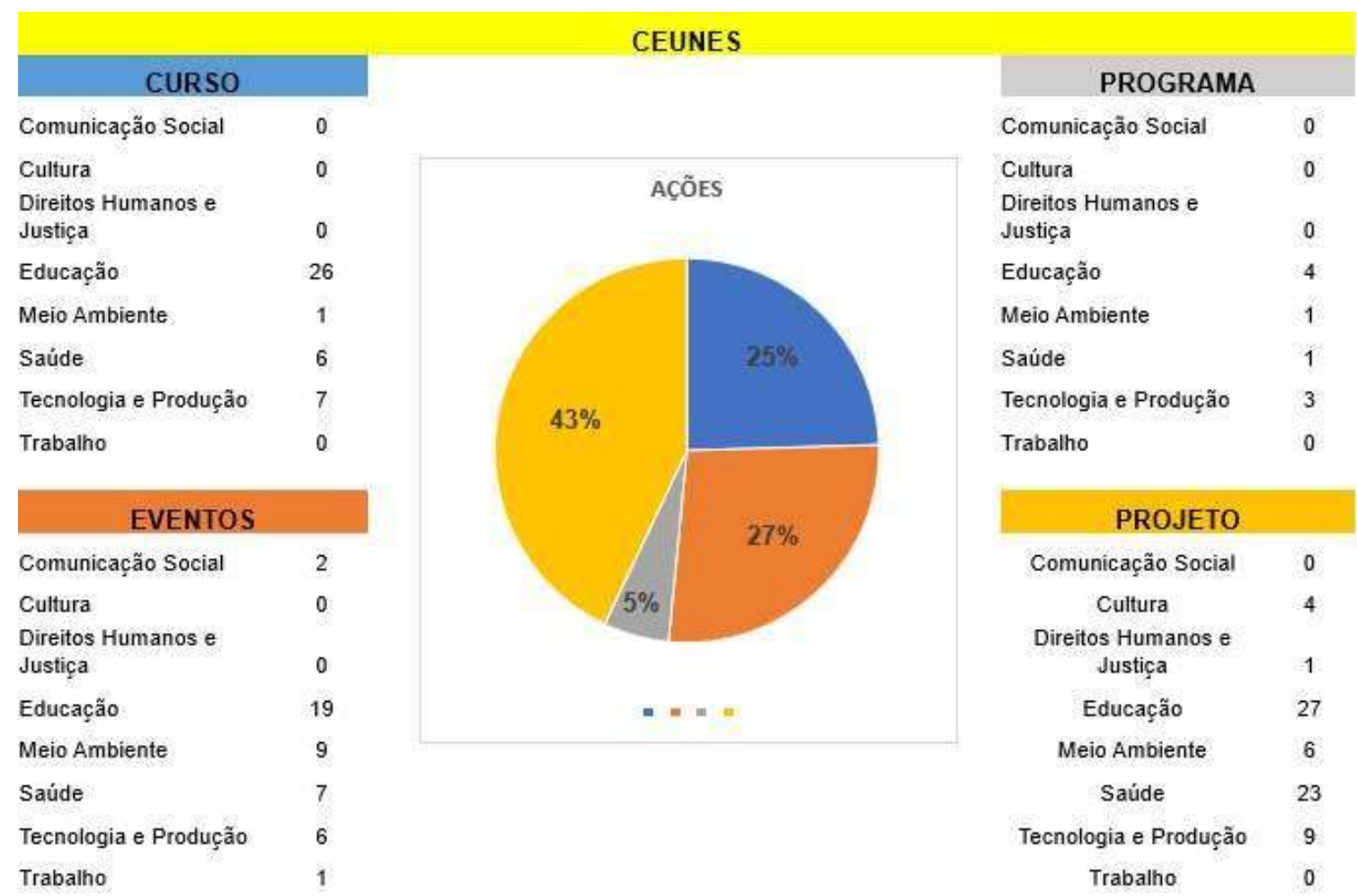

Fonte: SIEX/2019.

A ação que menos se destacou foi a classificada como Prestação de Serviço, com registro de duas ações. Posto isso, elas não foram incluídas no gráfico, mas destaca-se que a escolha da área foi de Direitos Humanos e de Meio Ambiente. Ressalta-se que os filtros de pesquisa disponibilizados na base de dados do SIEX não permitem realizar levantamento de atividades de extensão por curso o qual permitiria uma comparação com os PPCs.

Considerando que no âmbito da UFES, até o mês de janeiro de 2020, ainda não possuía Resolução para normatizar a curricularização da extensão, a pesquisa nos PPCs foi guiada pela normativa orientadora (Resolução $\mathrm{n}^{\circ} .7 / 2018 / \mathrm{CNE}$ ). Para tanto, o DDP/PROGRAD disponibilizou os 16 PPCs (versão corrente) dos Cursos de Graduação (Quadro 2). 
Quadro 2 - Projetos Pedagógicos de Curso do CEUNES - ano implementação (VERSÃO)

\begin{tabular}{|l|c|l|c|}
\hline \multicolumn{1}{|c|}{ CURSO } & VERSÃO & \multicolumn{1}{c|}{ CURSO } & VERSÃO \\
\hline Agronomia & 2006 & Engenharia de Petróleo & 2006 \\
\hline Ciência da Computação & 2011 & Engenharia de Produção & 2010 \\
\hline Ciências Biológicas-Bacharelado & 2018 & Farmácia & 2006 \\
\hline Ciências Biológicas- Licenciatura & 2009 & Física - Licenciatura & 2009 \\
\hline Educação do Campo & 2019 & Matemática-Licenciatura & 2018 \\
\hline Enfermagem & 2019 & Matemática Industrial & 2013 \\
\hline Engenharia de Computação & 2006 & Pedagogia & 2014 \\
\hline Engenharia Química & 2012 & Química & 2009 \\
\hline
\end{tabular}

Fonte: Elaborado pela autora a partir de dados do DDP/PROGRAD.

Observa-se que 68,75\% dos PPCs dos Cursos de Graduação do CEUNES foram criados (e ainda estão vigentes) no período anterior à instituição do PNE (2014-2024). Esses cursos trazem, na sua organização curricular, a Extensão como Atividades Curriculares Complementares (participação em eventos na área específica do curso; participação em projetos, programas ou serviços de extensão; apresentação de trabalhos provenientes de atividades de extensão em eventos) (IMPERATORE et al., 2015).

Verificou que nos PPCs anteriores a 2014 que as Atividades Complementares têm ações inseridas com natureza pedagógica e normativa, diferente da esperada para atender o PNE (2014-2024). Aponta-se, nestes documentos, que o que é praticado e classificado como atividades desenvolvidas na área de Extensão, os alunos participam das ações comoouvintes e não, necessariamente, envolvem a comunidade externa, não há troca de conhecimento e interação dialógica. Diferentemente do que é enfatizado pelos autores (FROS, 2017; RESENDE et al., 2017; CORTEZ et al., 2019) no processo de curricularização.

Posteriormente ao PNE (2014), apenas 31,25\% dos cursos possuem PPCs criados e, ou reformulados. Entretanto, destaca-se que após a publicação da Resolução No ${ }^{\circ}$ 07/2018/CNE, não ocorreram alterações nos PPCs do CEUNES a fim de inserção da extensão em quantidades significativas, pois se verifica que dos $5(31,25 \%)$ criados a partir de 2014 , somente $2(40 \%)$ foram no ano de 2019.

Baseando-se nos 5 PPCs que puderam ser analisados, os quais foram criados e, ou aprovados, a partir de 2014, a integralização de créditos, pela participação dos estudantes nas atividades de extensão, foi citada somente em 3 PPCs (Ciências Biológicas-Bacharelado; Enfermagem e Educação do Campo). No entanto, a forma de integralizar o percentual de créditos não ficou evidente e ainda foi apresentada de forma diversa e insuficiente para o cumprimento da estratégia estabelecida no PNE e na Resolução No N $^{\circ}$ 007/2018, ou seja, o percentual da carga horária para atividade extensionista, o protagonismo discente e o envolvimento da comunidade externa não foram identificados. 
Não foi localizado nenhum PPC que contenha disciplina de extensão (apesar de não ser uma diretriz e muito menos uma ação taxativa praticada por outras universidades que se encontram em etapas mais avançadas no processo de curricularizar). Apenas o Curso de Educação no Campo relata que possui uma disciplina de natureza mista (teórica/prática), isto é, possui atividades de extensão integradas nos conteúdos teóricos.

O PPC que mais relaciona ações de extensão e demonstra interação e possibilidade de troca com a sociedade, referenciando às necessidades sociais da região em que o CEUNES está inserido é o Curso de Enfermagem. É perceptível a valorização deste sobre o conhecimento produzido em sala de aula e a reprodução fora dos muros da academia. Este comportamento vem ao encontro do processo histórico da extensão, na perspectiva assistencialista, apoiada no movimento estudantil (UNE) e no período militar (ALMEIDA, 2011; INCROCCI e ANDRADE, 2018) e da prática em uma das áreas mais tradicionais da política de extensão: a saúde.

Os 2 PPCs (Cursos de Educação do Campo e Enfermagem) que foram reformulados posteriormente à Resolução $n^{\circ}$. 7/2018 também não realizaram a creditação da extensão de acordo com as diretrizes. Tal fato evidencia que o CEUNES ainda não conseguiu efetivar a curricularização da extensão após vigência das legislações que apontam a obrigatoriedadeda inserção da extensão na matriz curricular.

De modo a atender ao último objetivo específico, verificar junto ao Presidente do NDE e dos Coordenadores de Cursos os seus os seus conhecimentos e ou ações quanto à meta 12 , estratégia 12.7 estabelecida no PNE (2014-2024) foi enviado aos mesmos o questionário. As perguntas foram organizadas e agrupadas em três grandes blocos: mapeamento das ações de extensão; extensão e formação acadêmica e curricularização, conforme Figura 2. 
Figura 2 - Estrutura da entrevista
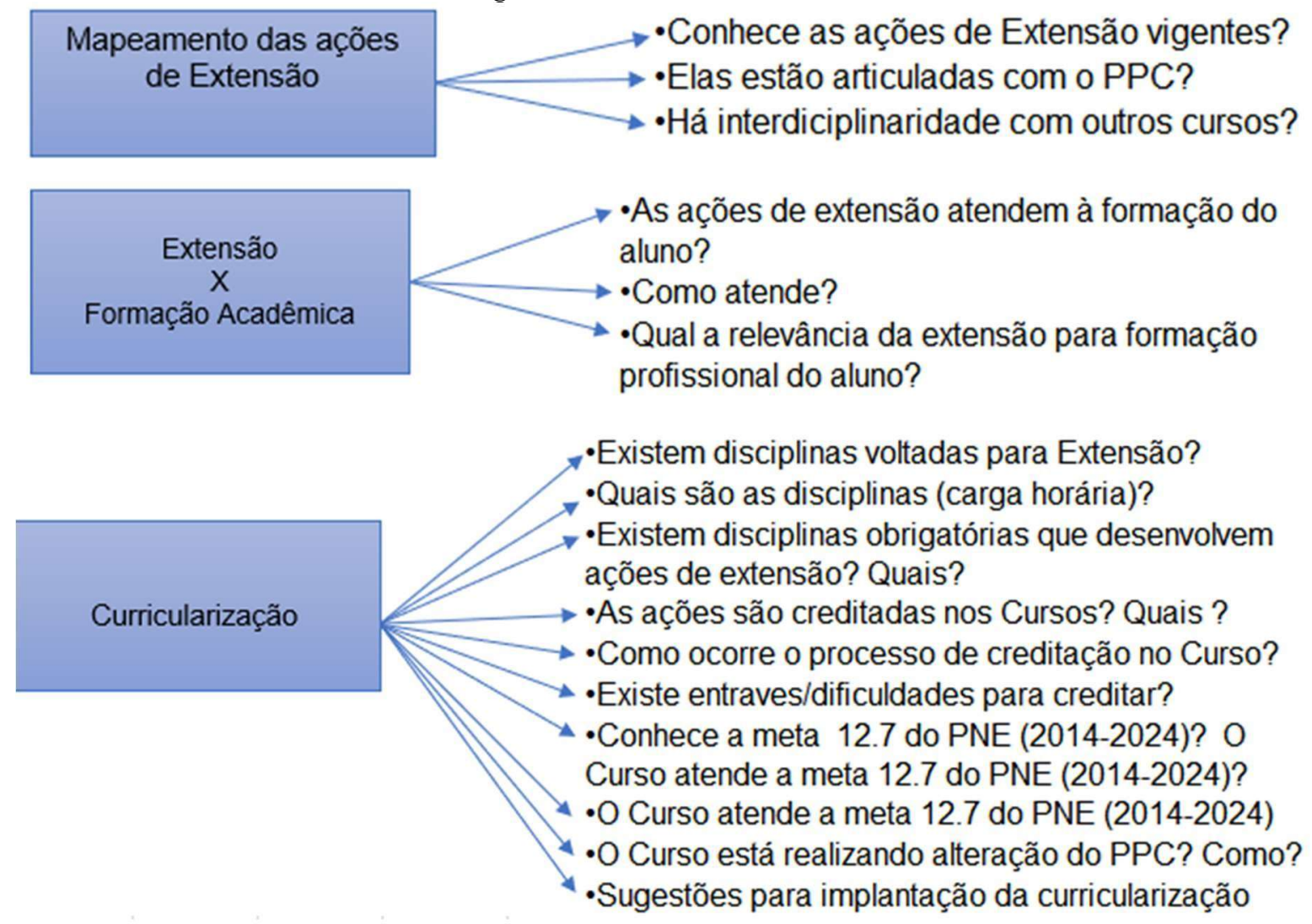

Fonte: Elaborado pela autora, 2019.

Dos 31 questionários distribuídos houve devolutiva de 27, sendo 13 respostas de Presidentes dos NDEs e 14 de Coordenadores de Curso de Graduação. Vale ressaltar que para fins de tratamento de dados, o quantitativo de 27 respondentes representará os $100 \%$ dos dados analisados. De modo a facilitar a análise as respostas foram tabuladas em áreas: Humanas (Curso de Pedagogia e Educação do Campo); Exatas (Ciência da Computação, Engenharia Química, Engenharia de Petróleo, Engenharia de Produção, Engenharia de Computação Física, Química, Matemática e Matemática Industrial) e Agrárias e Biológicas (Agronomia, Ciências Biológicas - Licenciatura e Bacharelado, Farmácia e Enfermagem).

Quando questionados sobre o conhecimento dos programas e projetos de extensão vigentes nos respectivos cursos, 77,8\% dos respondentes indicaram que conhecem as ações de extensão desenvolvidas. Contudo, quanto às suas articulações no PPC, somente 44,4\% responderam que sim. Esse resultado não está em conformidade com o compromisso pactuado pelo FORPROEX (2012), que orienta a inserção das ações extensionistas nos PPCs. Outro dado que chamou atenção foi que $33,3 \%$ dos respondentes optaram em não responder sobre a articulação da extensão no PPC. 
De forma sequencial, indagou-se sobre o envolvimento dos docentes nas ações de extensão e sua interação em ações de outros cursos. Dos 27 respondentes, $66 \%$ disseram que há docentes nos respectivos cursos que coordenam ações em outros. Esse resultado reafirma que as práticas extensionistas podem e devem permear conteúdos em diversas áreas do conhecimento, na perspectiva interdisciplinar (FORPROEX, 2012).

Os respondentes apontaram que a maior interação entre docentes ocorre na área de Ciências Agrárias e Biológicas (Agronomia, Ciências Biológicas Licenciatura e Bacharelado, Farmácia e Enfermagem). Segundo Oliveira e Goulart (2015), o estabelecimento de uma proposta de interdisciplinaridade e interprofissionalidade supera a visão generalista, ou especializada dos cursos, e a extensão, nesse contexto, ocorrerá de forma transformadora.

O segundo grupo de respostas procurou investigar se as ações de extensão desenvolvidas nos respectivos cursos atendem à formação dos alunos e como isso ocorre. Na questão objetiva, $59 \%$ dos entrevistados afirmam que elas atendem sim. Quanto à maneira que elas atendem, apenas $40 \%$ descreveram como ocorre esse processo de formação por meio das atividades extensionistas. Para a maioria dos coordenadores de curso e presidentes dos NDEs, a relação da extensão com a formação do aluno está baseada na possibilidade que a universidade tem de "mostrar os conhecimentos produzidos", "socializar conhecimentos além muros". As expressões "socializar e além muros" foram usados por vários respondentes, permitindo a inferência de que a universidade deve sair e levar o conhecimento produzido em seu espaço.

De forma conceitual, o FORPROEX trouxe a extensão como uma trajetória de mão dupla, ou seja, trouxe discussões (desde a criação do primeiro conceito de extensão) que a academia deve levar o conhecimento científico para fora da universidade, como também é possível trazer, de fora para dentro da academia, conhecimento empírico.

Quanto ao diagnóstico das contribuições que as ações de extensão proporcionam aos alunos, durante o processo de formação profissional, 78\% apontaram sobre sua relevância. Baseado nas respostas, identifica-se uma visão teórica que a extensão é o elo entre o saber científico e o popular e que manter a Extensão nos currículos é estreitar a teoria e prática (MARTINS, 2016).

O terceiro agrupamento de respostas procura elucidar acerca da curricularização da extensão nos cursos de graduação do CEUNES. Quanto à análise referente à existência de disciplinas voltadas para a extensão, observa-se que a área de exatas apresentou o maior percentual $(73,33 \%)$ de respostas negativas. Tal resultado vem corroborar com a teoria de Carneiro et al. (2014) e Fros (2017). Inverso ao cenário de exatas, encontra-se a área de humanas, a qual apresenta que em seus 2 cursos (100\%) existem atividades extensionistas nas disciplinas.

Evidencia-se, nesta mesma questão, respostas contraditórias. Dentre os 9 cursos da área de Exatas, 3 cursos apresentaram divergências entre o coordenador e o respectivo presidente do NDE, ou seja, alguns coordenadores responderam que ocorre a curricularização da extensão nos PPCs; entretanto, os presidentes dos NDEs disseram que não ocorre. 
Sobre as disciplinas voltadas para a Extensão, as respostas dos 12 respondentes que manifestaram positivamente sobre sua existência, confirmam a teoria de Imperatore et al. (2015), isto é, os componentes curriculares citados foram Estágio Supervisionado e Atividades Complementares, logo, não é a concepção desejada para atender o processo de curricularização orientado pela Resolução N. ${ }^{\circ} 7 / 2018$.

Apontam-se dificuldades dos coordenadores e presidentes dos núcleos para responderem se há disciplinas obrigatórias que desenvolvem ações de extensão. Entre os pares, somente $62 \%$ se posicionaram nas questões objetivas. Desse percentual, 50\% apresentaram respostas contraditórias. Ressalta-se, ainda, a escassez de informações quanto à especificação das disciplinas.

Com relação à prática da curricularização, do universo dos respondentes, 70,4\% disseram que as ações de extensão são creditadas nos PPCs. Eles estão distribuídos nas seguintes áreas: 27,3\% da área de Ciências Agrárias e Biológicas; 33,7\% Exatas e 9,4\% de Humanas.

Quando questionados sobre quais ações de extensão são creditadas, os respondentes dos 16 cursos indicaram que as ações são do tipo: projetos, eventos e cursos, apresentando o mesmo percentual de $68,75 \%$. As ações classificadas como programas, prestações de serviços e outros, foram 43,75\%, 37,5\% e 18,75\%, respectivamente. As ações citadas como "outros" são: Atividade Complementar, Atividade de Ensino e Trabalho de Conclusão de Curso.

Esse dado é relevante, pois no PNE (2014-2024), os 10\% que devem ser assegurados nos currículos relacionam-se às ações (de forma prioritária) do tipo projeto e programa e a Resolução $n^{\circ} 7 / 2018$ considera que todas as ações podem ser creditadas na matriz curricular. Sendo assim, de acordo com os respondentes, no CEUNES, todos os tipos de ações são praticados (mesmo de forma desproporcional).

Dos respondentes, apenas 10 se pronunciaram quanto à forma com que acontece $o$ processo de creditação. Parte das respostas (40\%) se apresentaram insatisfatórias, como: "procurar informações com coordenadores dos projetos ou portal da PROEX"; "solicitação no portal do aluno"; "no departamento"; "Projeto Pedagógico de Curso". Para os demais, 60\% disseram que realizam a creditação por meio de Atividades Complementares.

Quanto ao questionamento relacionado aos entraves e dificuldades para inserir, na matriz curricular, o mínimo de $10 \%$ da carga horária total em Extensão, foi constatado ser a questão discursiva que apresentou a menor participação dos respondentes, ou seja, $15 \%$ emitiram opinião. Esses apontamentos estão elencados no Diagrama de Causa e Efeito (Figura 3). 
Figura 3 - Levantamento de dificuldades para implementação da Meta 12.7 (PNE-2014-2024) no CEUNES

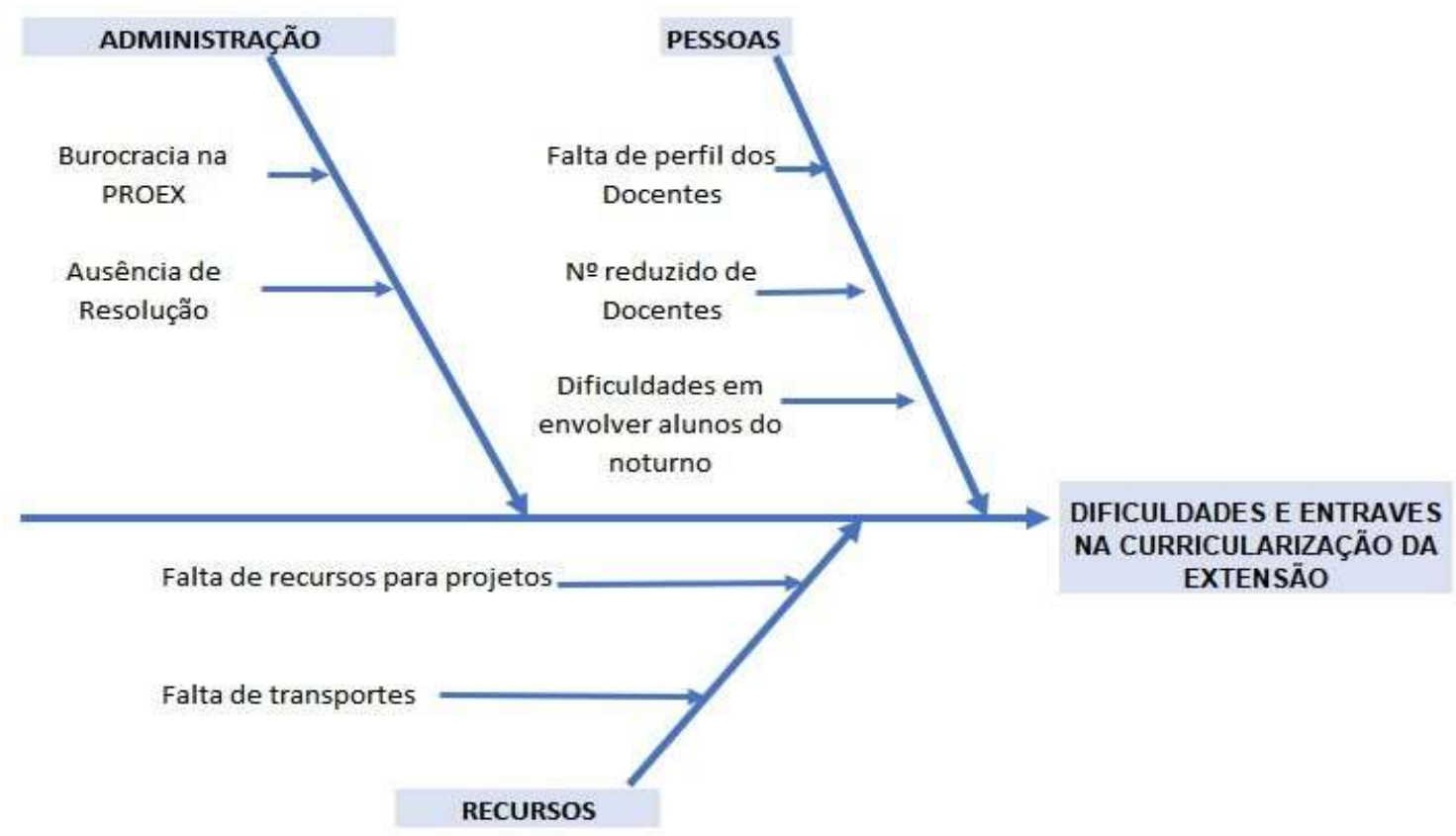

Fonte: Informações retirados a partir da análise dos questionários, 2019.

Avaliando o aspecto legal da curricularização, quanto ao conhecimento da meta 12.7 do PNE (2014-2024), 22 respondentes afirmaram conhecer a determinação que as atividades de extensão devem compor, no mínimo, $10 \%$ do total da carga horária curricular; 3 não conhecem a legislação e 2 não responderam.

Quando questionados se o curso está realizando alterações no PPC para atender a meta 12.7 do PNE (2014-2024), 75,0\% dos respondentes da área de Ciências Biológicas; 60,0\% Exatas e $25,0 \%$ de Humanas manifestaram que estão realizando. Destacam-se informações contraditórias dos cursos da área de Ciências Biológicas, quando os respondentes disseram que conhecem a meta, atendem a meta, mas estão alterando o PPC para creditar a extensão.

O questionamento realizado sobre as formas sugeridas para atenderem a creditação. Houve destaque para: criação de disciplina obrigatória (31\%); adequação de disciplinas (13\%). No mais, apresentação de respostas insatisfatórias, isto é, não definiram como realizar a inserção da extensão na matriz curricular, apenas citações vagas que o curso está realizando alteração no PPC (6\%) e 50\% não responderam essa pergunta. 
A última questão solicitou que os respondentes emitissem sugestões para implementação da creditação da extensão nos PPCs dos Cursos do CEUNES. Entre as mais citadas pelos Coordenadores de Curso e Presidentes dos NDEs, estão: disponibilidade de recursos financeiros, desburocratização dos registros e acompanhamento das atividades de extensão. Em linhas gerais, as respostas e até mesmo suas ausências permitiram criar um Plano de ação para o CEUNES, tornando, assim, o produto desta pesquisa.

\section{Considerações Finais}

Analisar a inserção de atividades de extensão nos currículos pedagógicos dos cursos de graduação da UFES - Campus São Mateus, conforme estabelecido na estratégia 12.7, do Plano Nacional de Educação 2014-2024, foi o objetivo geral desta pesquisa. Assim, ao finalizar a presente análise, destacam-se os resultados relevantes que emergiram do trabalho.

Observou-se que não existe um modelo a seguir de definição de curricularização da extensão. As IES têm autonomia e a Resolução $n^{0} 7 / 2018$ apenas orienta e respeita essa independência. Entretanto, ela dita algumas normas que devem ser cumpridas, tais como: a extensão como componente curricular no PPC do curso e participação da comunidade externa.

Quanto ao que foi considerado como banco de dados, para análise da inserção da extensão nos cursos de graduação do CEUNES, pôde-se concluir: número baixo de registros de ações, quando analisado o período de 14 anos (2006-2019); quanto aos tipos de ações, o destaque foi Projetos (43\%) e Eventos (27\%). Entretanto, diante do preconizado pelo PNE (20142024), esse resultado revela que para ocorrência da curricularização no CEUNES, entre outras atitudes por parte dos docentes, também será preciso avançar nas práticas relacionadas aos Programas junto à comunidade acadêmica, pois elas são inexpressivas.

Os 11 Projetos Pedagógicos de Curso, criados anteriormente às normativas da curricularização, a extensão é inserida como Atividades Complementares. Estas são idealizadas de forma mais livres, mais conectadas com experiências culturais que serão adquiridas, mas não compartilhadas. Nos documentos que foram reformulados, a partir das normativas (5), também não constam a extensão na matriz curricular. Assim, elas não atendem à estratégia 12.7 (PNE-2014-2024) e às diretrizes da Resolução No. 7/2018-CNE.

A partir da análise dos PPCs, é possível afirmar que a ausência de uma Resolução, da UFES, que estabeleça instruções de como operacionalizar a obrigação dos $10 \%$ da carga horária dos cursos de graduação em atividades de extensão, contribui para a morosidade das alterações curriculares.

Quanto à contribuição dos Coordenadores de Curso e Presidentes dos NDEs, descreve-se que todos os cursos necessitam discutir de que forma irão alcançar a curricularização $O$ processo de alteração nos currículos ainda é incipiente e necessita compreensão diante da ausência de respostas quando perguntado sobre a forma que ocorre a curricularização. 


\section{Referências}

ALMEIDA, A. L. Do humanismo ao assistencialismo: o CRUTAC no Estado Militar (1966-1985). 2011. 297 f. Tese (Doutorado em Educação) - Universidade Federal de Uberlândia, Uberlândia, 2011.

ANDRADE, R. M. M.; MOROSINI, M. C.; WIEBUSCH, E. M. Desafios Contemporâneos da Extensão Universitária: da invisibilidade a curricularização. In: X CONGRESSO IBERO AMERICANO DE DOCÊNCIA UNIVERSITÁRIA - CIDU, 10., 2018. Anais... Porto Alegre, 2018.

BENETTI, P. C.; SOUZA, A. I.; SOUZA, M. H. N. Creditação da extensão universitária nos cursos de graduação: relato de experiência. Revista Brasileira de Extensão Universitária, v. 6, n. 1, p. 25-32, jan./jun. 2015.

BRASIL. Constituição (1988). Constituição da República Federativa do Brasil. Brasília, DF: Presidência da República. Disponível em:

http://www.planalto.gov.br/ccivil_03/Constituição/Constituição.htm. Acesso em: 04 jul. 2019.

BRASIL. Lei n⿳0. 10.172, de 09 de jan. de 2001. Aprova o Plano Nacional de Educação. Disponível em:_http://portal.mec.gov.br/arquivos/pdf/L10172.pdf. Acesso em: 18 nov. 2018.

BRASIL. Instituto Nacional de Estudos e Pesquisas Educacionais Anísio Teixeira. Plano Nacional de Educação PNE 2014-2024: Linha de Base. - Brasília, DF: Inep, 2015. Disponível em: http://portal.inep.gov.br/documents. Acesso em: 18 nov. 2019.

BRASIL. Resolução no . 7, de 18 de dezembro de 2018. Estabelece diretrizes para a Extensão na Educação Superior Brasileira e regimenta o disposto na meta 12.7 da Lei $\mathrm{n}^{\circ}$ 13.005/2014 que aprova o Plano Nacional de Educação - PNE 2014-2024 e das outras providências. Diário Oficial da União, Seção 1, Brasília, DF, ed. 243, p. 49, 10 dez. 2018.

CARNEIRO, P. C. O.; COLLADO, D. M. S.; OLIVEIRA, N. F. C. Extensão universitária e flexibilização curricular na UFMG. Interfaces - Revista de Extensão, Belo Horizonte, v.2, n. 3, p. 4-26. jul./dez. 2014.

CORTEZ, J.; et.al. A curricularização da extensão no curso de licenciatura em física da universidade de Passo Fundo. Revista Conexão, v. 15, n.2, p. 1650174, 2019.

DEBONI, T. M. Z. G. $1^{\circ}$ Encontro de Creditação da Extensão Universitária. São Mateus, 2019. Palestra ministrada aos professores, alunos e técnicos do CEUNES/UFES em 27 ago. 2019. 
DEUS, S. HENRIQUES, R. L. M. A Universidade Brasileira e sua Inserção social. In: CASTRO, J. O.; TOMMASINO, H. (org.). Los caminhos de la extension em América Latina y el Caribe. Santa Rosa: Universidad Nacional de La Pampa, 2017. cap. 4, p. 77-92.

FÓRUM NACIONAL DE PRÓ-REITORES DE EXTENSÃO DAS UNIVERSIDADES PÚBLICAS BRASILEIRAS. Plano Nacional de Extensão Universitária. 2000-2001. Disponível em: https://proec.ufg.br/up/694/o/PNEX.pdf. Acesso em: 14 ago. 2019.

FÓRUM NACIONAL DE PRÓ-REITORES DE EXTENSÃO DAS UNIVERSIDADES PÚBLICAS BRASILEIRAS. Extensão Universitária: organização e sistematização. Belo Horizonte: Coopmed, 2007.

FÓRUM NACIONAL DE PRÓ-REITORES DE EXTENSÃO DAS INSTITUIÇÕES PÚBLICAS DE EDUCAÇÃO SUPERIOR BRASILEIRAS. Política Nacional de Extensão Universitária. Manaus: UFSC; Brasília; MEC/SESu, 2012.

FÓRUM NACIONAL DE PRÓ-REITORES DE EXTENSÃO DAS UNIVERSIDADES PÚBLICAS BRASILEIRAS. Conceito de extensão, institucionalização e financiamento. I FORPROEX. Editora Universitária UnB. Brasília: 1987. Disponível em : https://www.ufmg.br/proex/renex/images/documentos/1987-I-Encontro-Nacional-doFORPROEX.pdf. Acesso em: 18 nov. 2018

FROS, C. L. R. Curricularização da Extensão: sugestões para a implantação no curso de administração da Unipampa. 2017. 136 f. Dissertação (Mestrado Profissional em Gestão de Organizações Públicas) - Universidade Federal de Santa Maria/ UFSM, Santa Maria, RS, 2017.

GERHARDT, T. E.; SILVEIRA, D. T. Métodos de pesquisa. 1. ed. Porto Alegre: UFRGS, 2009.

GIL, A. C. Como elaborar projetos de pesquisa. 5. ed. São Paulo: Atlas, 2010.

GODOY, A. S. Introdução à pesquisa qualitativa e suas possibilidades. Revista de Administração de Empresas. Rio de Janeiro, v. 35, n. 2, p.57-63, maio. 1995.

IMPERATORE, J. L. R.; IMPERATORE, S. L. B.; PEDDE, V. Curricularizar a extensão ou extensionalizar o currículo? Aportes teóricos e práticas de integração curricular da Extensão ante a estratégia 12.7 do PNE. In: COLÓQUIO INTERNACIONAL DE GESTÃo UNIVERSITÁRIA - CIGU, 15., Mar del Plata. Anais... Desafios da Gestão Universitária no Século XXI, 2, 3 e 4 de dez. 2015, Mar del Plata. 2015.

INCROCCI, L. M. M. C.; ANDRADE, T. H. N. O fortalecimento da extensão no campo científico: uma análise dos editais ProExt/MEC. Revista Sociedade e Estado, v. 33, n.1, p.189-214, jan./abr. 2018. 
MARTINS, J. Extensão Universitária como Prática Educomunicativa: Contribuições para a Flexibilização dos Projetos Pedagógicos. In: CONGRESSO BRASILEIRO DE CIÊNCIAS DA COMUNICAÇÃO, 34., 2016, São Paulo. Anais... São Paulo. 2016.

MELO NETO, J. F. Extensão universitária: bases ontológicas. In: NETO, J.F.M. (Org..). Extensão Universitária - diálogos populares. 1. ed. Pernambuco: Editora Universitária, 2002. cap. 1, p. 7-22.

NOGUEIRA, M. D. P. O Fórum de pró-reitores de Extensão das Universidades Públicas: um ator social em construção. Interfaces -Revista de Extensão, v. 1, n.1, p. 35-47, jul./nov. 2013.

OLIVEIRA, F.; GOULART, P. M. Fases e Faces da extensão universitária: rotas e concepções. Revista Ciências em Extensão, v.11, n.3, p. 8-27. 2015.

PAULA, J. A. A extensão universitária: história, conceito e propostas. Interfaces - Revista de Extensão, v. 1, n.1, p. 05-23, jul./nov. 2013.

RENEX. Rede Nacional de Extensão. Mapeamento da inserção da extensão nos currículos dos cursos de graduação das Instituições Públicas de Educação Superior Brasileiras. Disponível em:

https://www.ufmg.br/proex/renex/images/relat\%c3\%93rio_FINAL_MAPEAMENTO_INSERCAO _EXTENSAO_FINAL.pdf. Acesso em: 13 set. 2019.

RESENDE, M. C. F.; ALBUQUERQUE, L. M. de; MOREIRA, T. R.; BORGES, B. K. N. O. A curricularização das práticas de extensão na PUC Minas. Revista Interdisciplinar de Extensão, v. 1, n. 2, 2017.

SANTOS, A. P. F. Curricularização da extensão: Projeto Comunitário nos cursos de Graduação do Centro Universitário - Católica de Santa Catarina em Jaraguá do Sul. 2017. 111 f. Dissertação (Mestrado em Educação) - Pontifícia Universidade Católica de São Paulo, São Paulo, 2017.

SILVA, L. D. DA; CÂNDIDO, J. G. Extensão Universitária: conceitos, propostas e provocações. 1. ed. São Paulo: Metodista, 2014.

UNIVERSIDADE FEDERAL DA BAHIA. Pró-Reitoria de Extensão. Disponível em: https://proext.ufba.br. Acesso em: 27 set. 2019

UNIVERSIDAE FEDERAL DE ALAGOAS. Pró-Reitoria de Extensão. Guia para curricularização da extensão na UFAL. Disponível em:

file://C:/Users/note_Downloads/guia-curricularizacao-da-extensao-na-ufal\%20(2).pdf. Acesso em: 27 set. 2019. 
UNIVERSIDADE FEDERAL DE SÃO PAULO. Comissão de estudo sobre a operacionalização dos $10 \%$ de atividades de extensão universitária na matriz curricular. Relatório Final. 2015. Disponível em: https://www.unifesp.br/reitoria/proex/curricularizacao/apresentacao-curricularizacao. Acesso em: 27 set. 2019.

UNIVERSIDADE FEDERAL DE PELOTAS. Pró-Reitoria de Extensão e Cultura. Guia de integralização da extensão. Disponível em: https://wp.ufpel.edu.br/prec/. Acesso em: 27 set. 2019.

UNIVERSIDADE FEDERAL DO ESPÍRITO SANTO. Pró-Reitoria de Graduação. Instrução Normativa N. 4, 2016. Disponível em: http://prograd.ufes.br/sites/prograd.ufes.br/files/field/anexo/instrucao_normativa_0042016_atualizada_em_28fev2018.pdf. Acesso em: 06 out. 2019.

UNIVERSIDADE FEDERAL DO ESPÍRITO SANTO. Pró-Reitoria de Extensão. Relatório de Gestão, 2008-2011. Acesso em: 01 out. 2019.

UNIVERSIDADE FEDERAL DO ESPÍRITO SANTO. Pró-Reitoria de Extensão. Relatório de Gestão, 2018. Acesso em: 01 out. 2019.

ZANFERARI, T. ALMEIDA, M. L. P. As metas do PNE (2001-2010 e 2014-2024) que discutem a Educação superior: (Des)continuidades e perspectivas. Revista Educere. p.3459-3470, 2017.

\footnotetext{
Notas

${ }^{i}$ Nomenclatura utilizada até 2012. Posteriormente, utilizou-se Fórum de Pró-Reitores das Instituições Públicas de Educação Superior Brasileiras.

ii 2008 - Resolução 041/2008 - Criação do Departamento de Educação e Ciências Humanas -DECH; 2009 Resoluções 006/2009 e 041/2009 - Criação do Departamento de Engenharias e Computação; Departamento de Ciências Matemáticas e Naturais; Departamento de Ciências da Saúde e Departamento de Ciências Agrárias e Biológicas; 2011 - Resolução 012/2011 - Divisão do Departamento de Ciências Matemáticas e Naturais para Departamento de Ciências Naturais e Departamento de Matemática Aplicada; 2012 - Resolução 064/2012 Divisão do Departamento de Engenharias e Computação para Departamento de Engenharias e Tecnologia e Departamento de Computação e Eletrônica.

iii Contabilizado os registros contendo relação nominal dos Docentes Efetivos que assumiram exercício no CEUNES no período de 2006-2019.
} 